\title{
EFEKTIVITAS PENEGAKAN HUKUM TINDAK PIDANA FIDUSIA DALAM PROSES PENYIDIKAN (STUDI DI POLRES BANYUMAS)
}

\author{
Oleh: Ridwan ${ }^{1}$
}

\begin{abstract}
This study is discussing about the effectiveness of law enforcer of fiduciary crime in the investigation process (case study; Polres Banyumas). This study is purposed to analyze the effectiveness or ineffectiveness of the law enforcer of fiduciary crime in the investigation process faced by the police investigator in the law enforcement of fiduciary crime act at Polres Banyumas.

The method of this study approach is using juridical sociology, research descriptive analyzes specification. This study was conducted at Polres Banyumas, the primary data of this study obtained by interviews the Satuan Reskrim Polres Banyumas (Banyumas Police Criminal Unit), the reporting party and reported party of fiduciary crime. Secondary data involves; legislation, literature, the research result of the legal experts, journals and campus. Data obtained by using literature study, served in a systematically and qualiitatively analyzed compiled narrative text.

Based of the study result and the discussion towards the research problems in this thesis, concluded as follows, that the investigation of law enforcement of fiduciary crime act at Polres Banyumas had been done but not yet effectively done caused, as follows: (1) The application of criminal sanctions in transferring object of fiduciary collateral does not raising a fear-effect to commit fiduciary crime, (2) The lack of public understanding of fiduciary legislation, (3) The implementation for investigation and supervision towards the case of fiduciary crime act has not yet optimized, (4) The case costs and the amount of investigator personnel are not balanced. The investigation process is constrained because of the legal regulation that have not been firmly related to the execution of fiduciary object collateral and the development of fiduciary crime act practice, cases that been taken care of by the investigator are excessive, the lack of supporting facility in the process of investigation and improvements of public needs. The effectiveness of law enforcement can be accomplished in the investigation process by an improvement the investigator ability, fulfillment of supporting facilities, improvement of supervision of the process of investigation and legal counseling to the public also improvement of the formation of fiduciary unit at the Polres.
\end{abstract}

Keywords : Fiduciary, Investigation, Law Enforcement.

\section{ABSTRAK}

Penelitian ini membahas efektivitas penegakan hukum tindak pidana fidusia dalam proses penyidikan (studi di Polres Banyumas). Penelitian ini bertujuan untuk menganalisis efektif atau tidak efektif penegakkan hukum tindak pidana fidusia dan menganalisis kendala yang dihadapi oleh Penyidik Kepolisian dalam penegakkan hukum tindak pidana fidusia di Polres Banyumas.

Metode pendekatan penelitian ini adalah yuridis sosiologis, spesifikasi penelitian deskriptif analisis. Penelitian dilakukan di Polres Banyumas, sumber data

\footnotetext{
${ }^{1}$ Polri, Banyumas, Email: ridwankoto96@ gmail.com
} 
primer dari penelitian ini adalah wawancara kepada personil Satuan Reskrim Polres Banyumas, pihak pelapor dan terlapor kasus tindak pidana fidusia. Sumber data sekunder meliputi peraturan perundang-undangan, literatur, hasil penelitian pakar hukum, jurnal dan kamus. Data diperoleh dengan menggunakan studi kepustakaan, disajikan dalam bentuk teks naratif yang disusun secara sistematis, dan dianalisis dengan kualitatif.

Berdasarkan hasil penelitian dan pembahasan bahwa penegakan hukum tindak pidana fidusia dalam proses penyidikan di Polres Banyumas terlaksana namun belum efektif hal ini disebakan: (1) Penerapan sanksi pidana dalam mengalihkan objek jaminan fidusia tidak menimbulkan efek takut untuk melakukan tindak pidana fidusia, (2) Kurangnya pemahaman masyarakat terhadap peraturan perundang-undangan fidusia, (3) Belum optimal pelaksanaan manajemen penyidikan dan pengawasan terhadap perkara tindak pidana fidusia, (4) Beban perkara yang tidak seimbang dengan jumlah personil penyidik. Proses penyidikan terkendala karena regulasi hukum yang belum tegas terkait eksekusi objek jaminan fidusia dan perkembangan modus tindak pidana fidusia, beban perkara yang ditangani penyidik terlalu banyak, kurangnya sarana pendukung dalam proses penyidikan serta meningkatnya kebutuhan masyarakat. Efektivitas penegakan hukum dapat diwujudkan dalam proses penyidikan dengan meningkatkan kemampuan penyidik, pemenuhan sarana pendukung, peningkatan pengawasan proses penyidikan dan penyuluhan hukum kepada masyarakat serta pembentukan unit fidusia ditingkat Polres.

Kata Kunci : Fidusia, Penegakan Hukum, Penyidikan.

\section{A. Pendahuluan}

Pemerintah membuat Undangundang Nomor 42 Tahun 1999 tentang Jaminan Fiduisa yang dalam penelitian ini disebut UUJF, untuk melindungi hak dan kepentingan masyarakat dalam bidang usaha pendanaan yang sebagian besar melalui kegiatan pinjam-meminjam melalui perjanjian antar pihak. Perkara Tindak Pidana jaminan fidusia yang dilaporkan di Polres Banyumas Tahun 2016- Agustus 2018 sebanyak 129 (seratus dua puluh sembilan) laporan. Perkara jaminan fidusia yang ditingkatkan ke penyidikan 8 (delapan) dan dilimpahkan ke Kejaksaan 1 (satu) perkara.

Berdasarkan latar belakang tersebut diatas penulis tertarik untuk mengangkat serta menganalisis lebih lanjut permasalahan terkait dengan efektivitas penegakan hukum tindak pidana fidusia dalam proses penyidikan di Polres Banyumas. Efektivitas hukum diartikan keberhasilgunaan hukum, berkenaan dengan keberhasilan pelaksanaan hukum. $^{2}$

Gustav Radbruch menyatakan dalam pencapaian tujuan hukum harus menggunakan prioritas, di mana prioritas pertama ialah keadilan, kemudian kemanfaatan, dan terakhir barulah kepastian yang disebut dengan

${ }^{2}$ Dahlan, Problematika Keadilan dalam Penerapan Pidana Terhadap Penyalah Guna Narkotika, Budi Utama, Yogyakarta, 2017, Hlm. 185 


\begin{abstract}
asas prioritas baku. ${ }^{3}$ Penegakan hukum terletak pada kegiatan menyerasikan hubungan nilai-nilai yang terjabarkan di dalam kaidahkaidah yang mantap dan mengejawantah dan sikap tindak sebagaimana rangkaian penjabaran nilai tahap akhir, untuk menciptakan, memelihara, dan mempertahankan kedamaian pergaulan hidup. ${ }^{4}$

Teori Lawrence M. Friedman tentang efektivitas penegakan hukum dalam perspektif sosiologi mengemukakan bahwa efektif dan berhasil tidaknya penegakan hukum tergantung tiga unsur : ${ }^{5}$
\end{abstract}

a. Struktur Hukum (legal structure)

"To begin with, the legal sytem has the structure of a legal system consist of elements of this kind: the number and size of courts; their jurisdiction ...Structure also means how the legislature is organized ...what procedures the police department follow, and so on. Strukture, in way, is a kind of crosss section of the legal system...a kind of still photograph, with freezes the action."

Struktur hukum dalam penegakan hukum merupakan

${ }^{3}$ Achmad Ali, Menguak Tabir

Hukum, Fajar Interpratama, Jakarta, 2017, Hlm. 99

${ }^{4}$ Soerjono Soekanto, Faktorfaktor yang Mempengaruhi Penegakan Hukum, Rajawali Pers, Jakarta, 2014, Hlm.5

${ }^{5}$ Lawrence M. Friedman (Terjemahan

Wishnu Basuki), Hukum Amerika Sebuah Pengantar, $2^{\text {nd }}$ Edition, PT Tata Nusa, Jakarta Indonesia, 2001, Hlm.7-11 lembaga-lembaga penegak hukum di pemerintahan, yang diberikan tugas dan wewenang yang diatur dan dilindungi secara undang-undang.

b. Subtansi Hukum (legal substance)

"Another aspect of the legal system is its substance. By this is meant the actual rules, norm, and behavioral patterns of people inside the system ...the stress here is on living law, not just rules in law books"

Peraturan sebenarnya, norma, dan pola sikap orang yang berada didalam sistem tersebut. Tekanan disini ada pada hukum kehidupan, bukan hanya pada peraturan yang terdapat di buku tentang hukum.

c. Budaya Hukum ( legal culture)

"The third component of legal system, of legal culture. By this we mean people's attitudes toward law and legal system their belief ...in other word, is the climinate of social thought and social force wich determines how law is used, avoided, or abused." 
Budaya hukum menekankan pada kepentingan masyarakat dan tekanan pada masyarakat yang menentukan bagaimana hukum dipatuhi, dilanggar, atau disalah gunakan.

Robert B seidman mengungkapkan bahwa bekerjanya hukum dimasyarakat dipengaruhi oleh all other personal force (semua kekuatan dari individu masyarakat) yang melingkupi seluruh proses. ${ }^{6}$

Untuk mengetahui bagaimana seseorang pemegang peran di dalam masyarakat akan bertindak, harus ditinjau dalam hubungannya dengan fungsi-fungsi dari faktor-faktor yang berhubungan dengan peran yang diharapkan (role expectation) dari orang itu, fungsifungsi itu adalah: ${ }^{7}$
a. Peraturan-peraturan hukum yang ditujukan kepada orang itu;
b. Sanksi-sanksi peraturan hukum tersebut;
c. Aktivitas lembaga penerap sanksi seperti: Kepolisian, Jaksa, Pengadilan;
d. Seluruh komplek kekuatan- kekuatan sosial, politik,

${ }^{6}$ Robert B Seidman, Law order and Power, Adition Pubblishing Company Wesley Reading massachusett, 1972, Hlm.93

${ }^{7}$ Ronny Hanitijo Soemitro.

1992. "The law of Nontransferability of Law Menurut Robert B. Seidman”. artikel dalam Majalah Masalah-Masalah Hukum Fakultas hukum Universitas Diponegoro Semarang No. 3 Tahun XII. ekonomi, yang

mempengaruhinya

Tindak Pidana Fidusia adalah apabila subjek hukum sudah memenuhi unsur perbuatan tindak pidana sebagaimana yang sudah ditentukan dalam ketentuan pidana Pasal 35 dan 36 Undang-Undang Nomor 42 Tahun 1999 Tentang Jaminan Fidusia, maka subjek hukum itu dipidana dengan pidana penjara dan denda.

Tindak pidana fidusia yang diatur khusus dalam pasal 35 dan 36 UUJF, Pasal 35 menegaskan sebagai berikut:

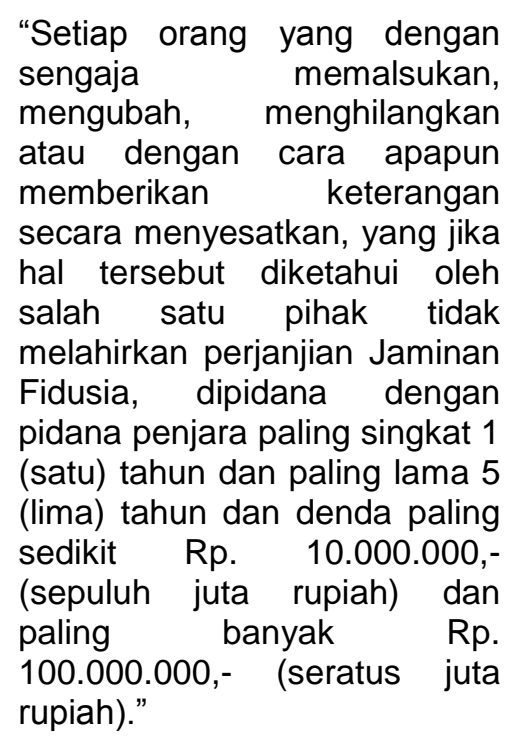

Sedangkan Pasal 36 menegaskan sebagai berikut:

"Pemberi Fidusia yang mengalihkan, menggadaikan, atau menyewakan Benda yang menjadi objek Jaminan Fidusia sebagaimana dimaksud dalam Pasal 23 ayat (2) yang 
1525 | Jurna I I d e a H u kum

Vol. $5 \mathrm{No} .2$ Oktober 2019

MagisterIImuHukum Universitas Jenderalsoedirman

dilakukan tanpa persetujuan tertulis terlebih dahulu dari Penerima Fidusia, dipidana dengan pidana penjara paling lama 2 (dua) tahun dan denda paling banyak Rp. 50.000.000,- (lima puluh juta) rupiah."

Ketentuan pidana fidusia berlaku ketika sahnya perjanjian yang dilakukan antar pihak yang melakukan perjanjian dan benda yang menjadi agunan bagi pelunasan utang sudah berada dalam penguasaan Debitur (pemberi fidusia) dengan ketentuan sepakat mereka yang mengikatkan dirirnya, kecakapan untuk membuat suatu perikatan, suatu hal tertentu, suatu sebab tertentu yang halal. ${ }^{8}$

Hakikat penyidikan dimulai sejak diketahui bahwa sesuatu peristiwa yang terjadi merupakan tindak pidana, dan adanya sangkaan bahwa seseorang telah melakukan suatu tindak pidana, kemudian penyidikan yang dilakukan itu harus berdasarkan cara-cara yang diatur oleh undang-undang. ${ }^{9}$

Adapun alat bukti yang sah sebagaimana diatur didalam Pasal 184 ayat (1) Undang-undang Nomor

${ }^{8}$ Abdussalam, legal Opinion Ketentuan Pidana Pasal 35 dan 36 Undangundang No.42 Tahun 1999 tentang Jaminan Fidusia, Universitas Tama Jagakarsa, 2012.

${ }^{9}$ Mulyadi, Kapita Selekta Hukum Pidana Kriminologi dan Viktimologi, Djambatan, Jakarta, 2007, Hlm.42
08 Tahun 1981 tentang Hukum Acara

Pidana, yakni sebagai berikut:

a. Keterangan Saksi

b. Keterangan Ahli

c. Surat

d. Petunjuk

e. Keterangan terdakwa

\section{B. Perumusan Permasalahan}

Berdasarkan uraian tersebut di atas, untuk mengetahui lebih dalam tentang permasalahan untama dalam penulisan ini dan menggali faktafakta, megumpulkan data secara tepat serta terarah, maka dapat dirumuskan permasalahan sebagai berikut:

1. Apakah efektif penegakkan hukum tindak pidana fidusia dalam proses penyidikan di Polres Banyumas?

2. Bagaimana kendala yang dihadapi oleh penyidik kepolisian dalam penegakan hukum tindak pidana fidusia di Polres Banyumas?

\section{Metode Penelitian}

Metode pendekatan penelitian hukum ini penulis akan menggunakan metode penelitian hukum yang bersifat Yuridis Sosiologis. Penelitian hukum yang sosiologis memberikan arti penting pada langkah-langkah observasi dan analisis yang bersifat empiriskuantitatif, maka sering disebut 
sociolegal research. Tipe penelitian yang akan digunakan dalam penelitian ini adalah bersifat deskriptif analisis yang menggambarkan peraturan perundang-undangan yang berlaku yang dikaitkan dengan teoriteori hukum positif yang menyangkut permasalahan yang sedang diteliti. ${ }^{10}$

Sumber data dalam penelitian ini, peneliti menggunakan dua sumber data, yaitu:

1. Sumber Data Primer

Peneliti menggunakan data hasil wawancara dengan penyidik dan penyidik pembantu reserse kriminal Polres Banyumas, pelapor dan terlapor perkara tindak pidana fidusia.

2. Sumber Data Sekunder

Data sekunder mencakup bahan norma, peraturan dasar, perundang-undangan serta kamus, ensiklopedia, indeks dan sebagainya. $^{11}$ Data yang telah dikumpulkan kemudian dianalisis dengan menggunakan pendekatan kualitatif. Uji validitas terkait dengan derajat kepercayaan data atau ketepatan data, uji validitas dalam penelitian ini dilakukan dengan triangulasi data hasil penelitian, yaitu dikonsultasikan kembali data yang telah

${ }^{10}$ Ronny Hanitijo Soemitro, Metode Penelitian hukum dan Yurimetri. Ghalia Indonesia, Jakarta, 1988, hlm. 98.

${ }^{11}$ Ibid., hlm. 114. dianalisa kepada informan dan pembimbing. ${ }^{12}$ Triangulasi data dilakukan uji validitas dari hasil wawancara, observasi, dan bahan-bahan pustaka dengan tiga komponen tempat, orang, dan dokumen yang saling terkait (paper, person, place).

\section{Hasil Penelitian dan Pembahasan}

1. Efektivitas Penegakan Hukum Tindak Pidana Fidusia dalam Proses Penyidikan

a. Data Primer

Praktik dalam penanganan perkara tindak pidana fidusia belum maksimal penyelesaiannya, masih banyak perkara yang masih belum diselesaikan penanganannya karena kekurangan personil dan banyaknya perkara yang ditangani. $^{13}$ Penyelesaian perkara secara mediasi atau perdamaian kedua belah pihak mempermudah proses penyidikan.

b. Data Sekunder

$\begin{array}{lr}\text { Robert B } & \text { seidman } \\ \text { mengungkapkan } & \text { bahwa } \\ \text { bekerjanya } & \text { hukum }\end{array}$

12 Sugiyono, Metode Penelitian Kuantitatif Kualitatif dan $R \& D$, Alfabeta: Bandung, 2008, hlm.274.

Wawancara dengan Ipda. Rizky, pada hari Jumat, 28 September 2018 (Kanit Tipiter Satuan Reskrim Polres Banyumas) 
1527 | Jurna I I d e a H u kum

Vol. 5 No. 2 Oktober 2019

MagisterIImuHukum Universitas Jenderalsoedirman

dimasyarakat dipengaruhi oleh all other personal force (semua kekuatan dari individu masyarakat) yang melingkupi seluruh proses. $^{14}$

a. Peraturan-peraturan hukum yang ditujukan kepada orang itu;

b. Sanksi-sanksi peraturan hukum tersebut;

c. Aktivitas lembaga penerap sanksi seperti: Kepolisian, Jaksa, Pengadilan;

d. Seluruh komplek kekuatan-kekuatan sosial, politik, ekonomi, yang mempengaruhinya

Laporan pengaduan dan Laporan Polisi tindak pidana fidusia yang diterima di Polres Banyumas selama tahun 2016 sampai 2018, Pengaduan terigister (121) Laporan Polisi (8) P21 (1). Penanganan tindak pidana fidusia ditangani secara khusus oleh Unit II Tipiter dan dibantu oleh unit lain berdasarkan kebijakan/disposisi

${ }^{14}$ Robert B Seidman, Law order and Power, Adition Pubblishing Company Wesley Reading massachusett, 1972, HIm.9-3 penanganan perkara dari Kasat Reskrim.

Pembentukan hukum dan implementasinya tidak akan lepas dari pengaruh terdapat diluar hukum, seperti faktor ekonomi, politik, budaya, pendidikan, kepentingan dan semua kekuatan dari individu dan masyarakat yan terdapat di luar proses. Fungsi-fungsi dari faktor-faktor yang berhubungan dengan peran yang diharapkan (role expectation) dari orang itu, fungsi-fungsi itu adalah: ${ }^{15}$

a. Peraturan-peraturan hukum yang ditujukan kepada orang itu;

UUJF menjadikan

suatu perbuatan merupakan tindak pidana yang dituangkan dalam pasal 35 dan pasal 36 dengan dengan konsekuensi hukuman penjara dan denda.

b. Sanksi-sanksi peraturan hukum tersebut;

Dalam pasal 36

UUJF dengan ancaman penjara 2 (dua) tahun dan denda paling banyak

15 Ronny Hanitijo Soemitro. 1992. "The law of Nontransferability of Law Menurut Robert B. Seidman". artikel dalam Majalah Masalah-Masalah Hukum Fakultas hukum Universitas Diponegoro Semarang No. 3 Tahun XII. 
50.000 .000 (lima puluh juta).

c. Aktivitas lembaga penerap sanksi seperti: Kepolisian, Jaksa, Pengadilan;

\section{Ketidak}

seimbangan penyidik dengan beban tugas penanganan perkara tindak fidusia mejadikan lamanya proses penanganan perkara. $^{16}$

d. Seluruh komplek kekuatankekuatan sosial, politik, ekonomi, yang mempengaruhinya

Porses penyidikan memberikan edukasi kepada masyarakat bahwa perbuatan mengalihkan, menggadaikan atau menyewakan benda yang menjadi objek jaminan fidusia merupakan tindak pidana. $^{17}$

\section{Kurangnya}

penanganan perkara dalam proses penyidikan di Polres Banyumas menjadikan tidak maksimalnya penyampaian bagaimana masyarakat untuk bertidak dalam memenuhi hak dan

\footnotetext{
${ }_{17}^{16}$ Ibid

17 Barda Nawawi Arief, Bunga Rampai Kebijakan Hukum Pidana (Perkembangan Penyusunan Konsep KUHP Baru), Kencana Prenada Media Group, Jakarta, 2008, hal. 1.
}

\author{
kewajiban selaku pihak \\ yang berkempentingan, \\ agar tidak menimbulkan \\ kerugian dari kepentingan \\ tersebut.
}

\section{Kendala Penegakan Hukum Tindak Pidana Fidusia Dalam Proses Penyidikan}

\section{a. Data Primer}

Beban perkara yang ditangani oleh masingmasing penyidik menjadi prioritas tersendiri oleh penyidik mana yang terlebih dahulu ditindak lanjuti. Faktor kepentingan dan pemahaman seorang peyidik akan mempengaruhi bagaimana penanganan terhadap perkara yang sedang ditangani.

\section{b. Data Sekunder}

Kendala dalam penegakan hukum tindak pidana fiduisa dalam proses penyidikan bisa dilihat dari tiga elemen yaitu Struktur Hukum (Legal Structur) dimana lembaga kepolisian sebagai penegak hukum, Subtansi Hukum (Legal Subtance) dimana aturan atau hukum yang ada dalam masyarakat, dan 
1529 | Jurna I I d e a H u k u m

Vol. $5 \mathrm{No} .20 \mathrm{ktober} 2019$

MagisterIImuHukum Universitas Jenderalsoedirman

\author{
Budaya Hukum (Legal \\ culture).
}

Hal-hal krusial dalam proses

penyidikan :
a. Penyidik tidak siap
b. Team Work / cross fungtional team work tidak efektif atau lemah.
c. Perbedaan pendapat terhadap kasus yang dianggap twiligt zone penerapan pasal; kewenangan penyidik.
d. Tidak memadainya dukungan anggara, peralatan dan teknologi.
e. Intervensi sementara pihak dengan kecendrungan vested interest
f. Adanya kendala dan masalah dalam penerapan manajemen penyidikan $^{18}$

Lawrence Friedmann, pada bukunya Legal Theory, menggambarkan bahwa hukum terdiri dari 3 (tiga) komponen utama, yakni, substansi, struktur dan budaya. ${ }^{19}$

18 Hanjar Sekolah Tinggi IImu Kepolisan, Op.Cit, HIm.31

${ }_{19}$ Lawrence M. Friedman (Terjemahan Wishnu Basuki), Hukum Amerika Sebuah Pengantar, $2^{\text {nd }}$ Edition, PT Tata Nusa, Jakarta - Indonesia, 2001, HIm.7-11 a. Struktur Hukum (Legal Structure)

\section{Penegakan}

hukum sangat tergantung

dari bagaimana

kemampuan manajerial penyidik untuk menyelesaikan perkara tindak pidana yang dilaporkan serta pengawasan terhadap pelaksanaan upaya-upaya penyidik dalam melakukan tindakan hukum. ${ }^{20}$

b. Subtansi Hukum

Sanksi dalam

Pasal 36 UUJF dengan ancaman pidana 2 (dua) tahun penjara tidak dapat dilakukan penahanan. ${ }^{21}$

c. Budaya Hukum

Penegakan hukum tindak pidana fidusia di wilayah hukum Polres Banyumas terjadi karena pemberi fidusia tidak timbul rasa takut serta kurangnya pengetahuan masyarakat 


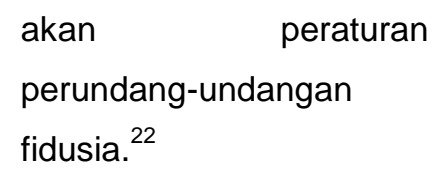

\section{E. Penutup}

\section{Simpulan}

Dari uraian di atas, maka dapat disimpulkan sebagai berikut:

1. Bahwa penegakan hukum tindak pidana fidusia dalam proses penyidikan di Kabupaten Banyumas belum efektif karena belum optimal aktivitas lembaga penerap sanksi dalam manajemen penyidikan dan pengawasan proses penyidikan, serta lemahnya sanksi hukum dalam peraturan perundang-undangan jaminan fidusia terkait perkembangan modus kejahatan tindak pidana fidusia yang semakin berkembang dengan terbentuknya kejahatan yang terpola menjadi kejahatan terorganisir.

2. Adapun hal-hal yang menjadi kendala dalam pelaksanaan penegakan hukum tindak pidana

$$
\begin{aligned}
& \text { fidusia dalam proses } \\
& \text { penyidikan di Polres } \\
& \text { Banyumas karena } \\
& \text { kurang tegasnya } \\
& \text { regulasi hukum terkait } \\
& \text { ketentuan eksekusi } \\
& \text { jaminan fidusia, jumlah } \\
& \text { personil penyidik yang } \\
& \text { tidak seimbang dengan } \\
& \text { beban perkara yang } \\
& \text { ditangani dan kurangnya } \\
& \text { sarana pendukung } \\
& \text { dalam proses } \\
& \text { penyidikan serta } \\
& \text { kurangya pengetahuan } \\
& \text { masyarakat terkait } \\
& \text { ketentuan perjanjian } \\
& \text { fidusia. }
\end{aligned}
$$

\section{Saran}

Kesadaran hukum masyarakat harus ditingkatkan dengan mengadakan penyuluhan hukum.Perlu pemerataan penanganan perkara yang melibatkan penyidik Polsek.

Meningkatkan pengawasan dan manajemen penyidkan terhadap penanganan perkara mulai dari SOP (standar operasional prosedur), serta pembentukan Unit Fidusia

\section{DAFTAR PUSTAKA}

${ }^{22}$ Wawancara dengan Akp.Bayu pada hari Jumat, 28 September 2018 (Kepala Satuan Reskrim Polres Banyumas) 
1531 | Ju rn a I I d e a H u k u m Vol. 5 No. 2 Oktober 2019

MagisterIImuHukum Universitas Jenderalsoedirman

Ali, Ahmad, 2009, Menguak teori hukum (legal theory) dan teori peradilan (judicialprudence), Prenada Media Group,Jakarta,

Ali, Achmad, 2017, Menguak Tabir Hukum, Fajar Interpratama, Jakarta.

Abdussalam, 2012, Ketentuan Pidana Pasal 35 dan 36 Undang-undang No. 42 Tahun 1999 tentang Jaminan Fidusia, Universitas Tama Jagakarsa.

Arief, Barda Nawawi, 2008, Bunga Rampai Kebijakan Hukum Pidana (Perkembangan Penyusunan Konsep KUHP Baru), Kencana Prenada Media Group, Jakarta,

Arief, Barda Nawawi, 2013, Kapita Selekta Hukum Pidana, ctk Ketiga, Citra Aditya Bandung.

Dahlan, 2017, Problematika Keadilan dalam Penerapan Pidana Terhadap Penyalah Guna Narkotika, Budi Utama, Yogyakarta.

Friedman,Lawrence M.,2001, Hukum Amerika Sebuah Pengantar, $2^{\text {nd }}$ Edition (Terjemahan Wishnu Basuki), PT Tata Nusa, Jakarta Indonesia

Hanjar Sekolah Tinggi IImu Kepolisan, Manajemen Penyidikan, Jakarta

Herujido,Yayat, 2001, Dasar-Dasar Manajemen, Gramedia Widiasarana, Jakarta.

Mulyadi, 2007, Kapita Selekta Hukum Pidana Kriminologi dan Viktimologi, Djambatan, Jakarta.

Robert B. Seidman". artikel dalam Majalah Masalah-Masalah Hukum Fakultas hukum Universitas Diponegoro Semarang No. 3 Tahun XII

Soemitro, Ronny Hanitijo, 1988, Metode Penelitian hukum dan Yurimetri. Ghalia Indonesia, Jakarta. $1992 . \quad$ "The law of
Nontransferability of Law

Soekanto, Soerjono, 2007, Pengantar Penelitian Hukum, UI/Press, Jakarta.

Sugiyono, 2008, Metode Penelitian Kuantitatif Kualitatif dan R\&D, Alfabeta: Bandung. https://www.suduthukum.com/2018/01/te ori-bekerianya-hukum.html dikases pada 29 November 2018 Aspek Hukum Pidana pada Perjanjian Fidusia.Universitas Sumatera Utara.

http://repository.usu.ac.id/bitstrea m/handle/123456789/64059/Chap ter\%20ll.pdf?sequence $=3$ \&isAllow ed $=y$ diakses pada 1 September 2018. 